\title{
Public Investment, Government Indebtedness and Transitional Dynamics
}

\author{
CONSTANTINE ANGYRIDIS \\ Ryerson University
}

\author{
PANAGIOTIS TSINTZOS* \\ Democritus University of Thrace
}

\begin{abstract}
This paper considers an endogenous growth model with public capital and government debt. In setting the level of public investment each period, the government is assumed to follow two fiscal rules that are commonly used in the growth literature: public investment is either equal to a constant fraction of output or equal to a constant share of tax revenues. In our model, we allow revenues to be raised by the government through progressive income taxation and bonds issue. For both fiscal rules, we show that the potential occurrence of either indeterminacy or instability crucially depends on whether the government is a debtor or a creditor. In particular, government indebtedness causes the economy to be prone to either belief-driven aggregate fluctuations or unstable dynamics. This is a novel result in the related literature which has largely overlooked the role of public debt as a possible contributing factor to the presence of indeterminacy and instability in growth models.
\end{abstract}

Keywords: Nonlinear Taxation, Endogenous Growth, Indeterminacy

JEL Classifications: E62; H41; H30; O40

\section{Introduction}

This paper studies the relationship between public debt and macroeconomic stability in the context of a representative agent model of endogenous growth. Modern macroeconomic theory has extensively studied the possibility of indeterminacy of equilibrium paths. ${ }^{1}$ In the context of growth theory, indeterminacy can take the form of multiple balanced growth paths (global indeterminacy), and/or multiple transition paths all of which converge to the same

\footnotetext{
* Corresponding Author. Tsintzos: ptsintzo@econ.duth.gr. Angyridis:cangyridis@economics.ryerson.ca

(C) 2018 Constantine Angyridis and Panagiotis Tsintzos; . Licensed under the Creative Commons Attribution - Noncommercial 3.0 Licence (http://creativecommons.org/licenses/bync/3.0/. Available at http: //rofea.org.

${ }^{1}$ For a concise survey on indeterminacy in macroeconomics, see Benhabib and Farmer (1999). In addition, Benhabib and Gali (1995) show that the data is not consistent with the dynamics of growth models that exhibit a unique transition path.
} 
long-run equilibrium (local indeterminacy). The presence of global indeterminacy may help explain why economies with similar fundamentals can have the same per capita income but grow at different rates. On the other hand, the presence of local indeterminacy may provide a rationale of why economies with the same growth rate can have different per capita levels of income.

The present paper analyzes the possibility of local indeterminacy when it is fiscal policy that generates externalities leading to long-run growth. Since the seminal studies of Arrow and Kurz (1970), Barro (1990) and Futagami et al. (1993), productive public capital has been considered as a key determinant of long-run growth. In general, fiscal policy is a key tool at the disposal of policymakers that can be used to stimulate growth, but also to ameliorate the effects of business fluctuations. Hence, the potential presence of indeterminacy or instability should be taken seriously into consideration in the design of fiscal policy since it may have significant welfare implications.

In this paper, we consider an endogenous growth model with public capital, progressive income taxation and government debt. We derive analytically the necessary and sufficient parametric space that ensures uniqueness of equilibrium (i.e. a unique balanced growth path) under two different taxation schemes (flat vs. progressive income taxes) and government expenditure rules (public investment expenditure indexed to output vs. public investment expenditure indexed to revenues). It is shown that, within this parametric domain, the possibility of local indeterminacy arises only when the government is a debtor and indexes public investment to tax revenues. In all other cases, the long-run equilibrium is either locally determinate in the saddle point sense or unstable.

Relative to the existing literature, our framework incorporates simultaneously two important features of actual fiscal policy: public debt and progressive taxation. As it is discussed below when reviewing the related literature, indeterminacy appears to be quite prevalent in growth models with a government that maintains a balanced budget in every period and uses flat rate taxes to raise revenues. Our analysis shows that progressive taxation is not important for the potential occurrence of indeterminacy. On the other hand, the presence of debt is a key factor in affecting the dynamics of the economy.

If the government is a creditor, it is shown that there is no indeterminacy or instability. In contrast, if the government is a debtor, then indeterminacy occurs only for a specific subset of the parametric space we consider. From this perspective, allowing the government to issue bonds or accumulate assets reduces the likelihood of indeterminacy relative to the balanced budget case. The only other possibility when the government is a debtor is that the economy exhibits unstable dynamics. Hence, the presence of public debt increases the likelihood of instability across the various cases considered. The occurrence of instability implies that even a small perturbation will cause the economy to permanently deviate from its long-run equilibrium. Furthermore, the economy may follow a dynamic path that violates the 


\section{ANGYRIDIS, TSINTZOS Public Investment and Debt}

principles of intertemporal optimization or present value budget constraints. For this reason, these outcomes are rendered in the related literature as infeasible.

The paper is organized as follows. Section 2 reviews the related literature and discusses our contribution. Section 3 presents the model. Section 4 defines the balanced growth path under the two fiscal rules used to finance public investment. Section 5 studies the transitional dynamics of the economy under either fiscal rule. Section 6 provided the main intuition behind our results and discusses their policy implications. Section 7 provides a numerical illustration of the theoretical results obtained in the previous section. The final section concludes. Proofs of the various propositions are relegated to Appendix A. Finally, Appendix B presents an extended version of our model.

\section{Related Literature}

Schmitt-Grohé and Uribe (1997) show that a standard one-sector RBC model with constant returns-to-scale production technology may exhibit indeterminacy and sunspots under a balanced-budget rule where fixed public expenditures are financed by proportional taxation on total income. Among others, Palivos et al. (2003), Park and Philippopoulos (2004) and Chen and Guo (2013a) obtain a similar result in an endogenous growth framework. By allowing the government to issue debt, our findings indicate that indeterminacy may occur even if the government does not maintain a balanced budget in every period.

In terms of the tax structure in our model, we assume that the government raises revenues using a progressive income tax schedule which is an empirically plausible assumption; see, for example, Arnold (2008). Our specification is based on Guo and Lansing (1998) who postulate that the tax rate an individual is facing is an increasing function of its taxable income relative to a benchmark level of income that is taken as given. Following Greiner (2006), this benchmark level corresponds to the average taxable income in the economy in our case. Guo and Lansing (1998) show in the context of the exogenous growth neoclassical model that a sufficiently progressive income tax schedule can ensure saddle path stability and stabilize the economy against sunspot fluctuations. Extending their framework in an endogenous growth setting, Chen and Guo (2013a) find that raising the tax progressivity may actually destabilize the economy with fluctuations driven by agents' self-fulfilling expectations. In contrast to both studies, we find that the degree of progressivity of the tax schedule does not make the economy more or less susceptible to indeterminacy.

In our model, we consider two fiscal rules that have been adopted in the related theoretical literature. The first rule is based on Devereux and Love (1995) and Turnovsky (2000), and indexes public investment every period to output. The second rule follows Greiner and Semmler (2000) and Ghosh and Mourmouras (2004), and indexes public investment to the tax revenues that are raised by the government every period. We show that, under either of these two rules, a unique balanced growth path equilibrium exists. However, these rules differ in 
terms of the possible stance of the government as a debtor or a creditor in the long-run equilibrium. It is shown that when public investment is indexed to tax revenues, the government is always a debtor. In contrast, when public investment is indexed to output, then the government can be either a debtor or a creditor. In turn, whether the government is a borrower or a lender determines the presence or absence of indeterminacy and instability in our model.

The paper closest to ours is that of Greiner (2006). The author develops an endogenous growth model with public capital, progressive taxation and government debt. The model is used to derive the necessary conditions for the existence of a sustainable balanced growth path. Furthermore, the author uses numerical methods to analyze the effects of changing the slope of the tax schedule on the dynamics of the economy and the long-run growth rate.

However, there are two major differences between our work and Greiner's. First, the author assumes that the instantaneous utility function is logarithmic in consumption. This is only a special case of the constant elasticity of intertemporal substitution (CEIS) utility function used in our specification. Second, Greiner assumes that the ratio of the primary surplus to output is a positive linear function of the debt-to-GDP ratio. We do not impose such a restriction. Instead, we consider two alternative fiscal rules. The first rule keeps the share of public investment in output constant. The second rule assumes that the share of public investment in total tax revenues remains fixed.2

In some earlier work on indeterminacy, Palivos et al. (2003) generalize the model of Barro (1990) by introducing an endogenous labor supply decision. It is shown that a continuum of equilibria and global indeterminacy can arise for reasonable parameter values. The public input that generates economy-wide increasing returns is a flow variable, while in our case it is a stock variable. Furthermore, the government finances the public production services through a flat income tax maintaining a balanced budget throughout, while in our model the government uses a progressive income tax schedule and issues debt.

Park and Philippopoulos (2004) use a standard one-sector endogenous growth model with inelastic labor supply, in which the government uses a flat income tax to finance public production and consumption services. They show that two balanced growth paths exist with substantially different properties: a low-tax and high-growth equilibrium, and a high-tax and

\footnotetext{
${ }^{2}$ This difference in specification is crucial, because it affects the transition path of the economy to the balanced growth path equilibrium. In Greiner's study, it is the transition path of public capital that adjusts to the dynamics of public debt: according to the author's fiscal rule, an increase in debt causes a reduction in public investment which reduces the stock of public capital. In our case, the causality runs the other way round: it is the transition path of public debt that adjusts to the dynamics of public capital. In other words, an increase in public investment causes an increase in debt under either of the two fiscal rules we consider (see equation (33) and footnote 5 below). This factor becomes important in our case because, in order for indeterminacy to be present, we require public capital to increase causing the after-tax return on capital to rise and, thus, validating the households' expectations.
} 


\section{ANGYRIDIS, TSINTZOS Public Investment and Debt}

low-growth equilibrium. Furthermore, there can also be an infinite number of transition paths all of which converge to either of the two long-run equilibria described above. In other words, the framework of Park and Philippopoulos allows for the presence of both global and local indeterminacy, while in our case only local indeterminacy is possible. Their framework differs from ours in two main aspects. First, their specification involves two types of expenditures financed through a flat tax with the government always maintaining a balanced budget. In contrast, we consider only one type of expenditure that is financed through a progressive income tax while, at the same time, the government can issue debt. Second, these authors conduct their analysis on indeterminacy based on an endogenously determined fiscal policy, while in our case fiscal policy is exogenous.

More recently, Chen and Guo (2013a) examine the interaction between economic growth and indeterminacy in a one-sector representative agent model of endogenous growth with a flow of productive public spending and nonlinear income taxation. The authors distinguish between two effects of an increase in government purchases: the demand-side effect, captured by the ratio of government purchases to output along the balanced growth path, and the supply-side effect, captured by the output elasticity of productive spending. It is shown that, if the supply-side effect outweighs the demand-side effect, then the economy exhibits an indeterminate balanced growth path equilibrium when the tax schedule is sufficiently progressive or regressive. On the other hand, when the supply-side effect is weaker, then indeterminacy arises under progressive income taxation. Compared to their work, we constrain ourselves to progressive taxation which is empirically prevalent relative to regressive taxation. Furthermore, we allow the government to issue debt and treat productive spending as a stock instead of a flow variable.

\section{The Model}

Consider a decentralized closed economy with three sectors: the household sector, which consists of a unit measure of identical infinitely-lived households, a production sector and the government. First, we describe the production sector which is represented by a single firm that behaves competitively and maximizes static profits. The aggregate production technology is given by:

$$
Q(t)=A K(t)^{1-\alpha}(L G(t))^{\alpha}
$$

where $Q$ denotes output, $K$ and $G$ represent the stock of private and public capital at time $t$, respectively, $L$ is the aggregate labor supply, $0<\alpha<1 / 2$ denotes the output elasticity with respect to public capital and $A>0$ is a scaling parameter. Public capital is assumed to be a non-rival and non-excludable public good that is labor-augmenting. The specification of 
production function (1) implies that households supply labor inelastically. For simplicity, aggregate labor supply $L$ is normalized to unity.

The optimality conditions for profit maximization by the firm yield the wage rate $\omega(t)$ and real interest rate $r(t)$, respectively:

$$
\begin{gathered}
\omega(t)=\alpha A K(t)^{1-\alpha} G(t)^{\alpha} \\
r(t)=(1-\alpha) A K(t)^{-\alpha} G(t)^{\alpha}
\end{gathered}
$$

Note that optimality condition (3) implies that the depreciation rate of private capital is assumed to be zero. ${ }^{3}$

The government's flow budget constraint is given by:

$$
\dot{B}(t)=r(t) B(t)-T(t)+I_{G}(t)
$$

where $\dot{B}(t)$ denotes the rate of change in the stock of public debt $B(t), T(t)$ represents the income tax revenues collected by the government and $I_{G}(t)$ is expenditure on public investment. The public debt accumulation equation (4) implies that the rate of return on government bonds $r(t)$ is equal to the rental rate of private capital.

Two alternative schemes are considered regarding the financing of public investment. Based on the studies by Devereux and Love (1995) and Turnovsky (2000), the first scheme sets public investment every period equal to a constant fraction $0<\psi_{1}<1$ of aggregate output. Formally:

$$
I_{G}(t)=\dot{G}(t)=\psi_{1} A K(t)^{1-\alpha} G(t)^{\alpha}
$$

Since public investment is indexed to output, we will refer to the policy rule given by expression (5) as FRO. Note that expression (5) implies that, as in the case of private capital, the depreciation rate of public capital is assumed to be zero.

Following Greiner and Semmler (2000) and Ghosh and Mourmouras (2004), the second financing scheme sets public investment every period equal to a constant fraction $0<\psi_{2}<1$ of tax revenues collected by the government:

$$
I_{G}(t)=\dot{G}(t)=\psi_{2} T(t)
$$

\footnotetext{
${ }^{3}$ The sole purpose of this assumption is to ease exposition. Our numerical simulations, as described in Section 7, show that our results extend to the case in which the depreciation rates of private and public capital are strictly positive. Appendix B provides a brief description of the extended version of our model that includes the two depreciation rates.
} 


\section{ANGYRIDIS, TSINTZOS Public Investment and Debt}

Since public investment is indexed to taxes, we will refer to the policy rule given by expression (6) as FRT.

The government raises revenues to finance public investment and service its debt by taxing the income earned by the households from supplying labor and holding assets:

$$
T(t)=\tau(t)(\omega(t)+r(t) W(t))
$$

where $W(t)$ denotes wealth. The latter is the sum of private capital stock and government bond holdings of households:

$$
W(t)=K(t)+B(t)
$$

Let $y(t)=\omega(t)+r(t) W(t)$ denote the income that the representative household earns in period $t$ and $Y(t)$ the economy-wide average income. Every period, the representative household faces a nonlinear income tax schedule given by:

$$
\tau(t)=1-\eta\left(\frac{Y(t)}{y(t)}\right)^{\varphi}
$$

where the parameters $\eta \in(0,1]$ and $\varphi \in[0,1)$ represent the level and slope of the tax schedule, respectively. The above specification for $\tau(t)$ is adopted from Guo and Lansing (1998) and Greiner (2006). Chen and Guo (2013b) apply the nonlinear least squares methodology of Cassou and Lansing (2004) and obtain year-by-year empirical estimates of the level and slope of tax schedule (9) based on the U.S. federal individual income tax schedule for the period 1966-2005. These estimations result in an average R-square of 0.867 . Hence, this specification captures well the progressive nature of the tax code of an advanced economy such as the United States.

Note that in the case when $\varphi>0$, tax rate $\tau(t)$ is monotonically increasing with the agent's income $y(t)$. In other words, if income at time $t$ is above $Y(t)$, then the household faces a higher tax rate compared to the case when income is below $Y(t)$. Hence, expression (9) represents a progressive income tax schedule.

By setting $\varphi=0$ and $\eta=1-\tau$ in (9), the progressive tax scheme collapses to a flat (constant) tax rate which is typically assumed in the growth literature. In this case, the representative household faces the constant tax rate $1-\eta$ regardless of the level of $y(t)$. Note also that in the presence of a progressive income tax schedule, the average and marginal tax rates do not coincide. In particular, the marginal tax rate which affects intertemporal decisions is equal to:

$$
\tau_{m}(t)=\frac{\partial(\tau(t) y(t))}{\partial y(t)}=1-\eta(1-\varphi)\left(\frac{Y(t)}{y(t)}\right)^{\varphi}
$$


The marginal tax rate exceeds the average tax rate since the latter is given by:

$$
\tau_{a}(t)=\frac{\tau(t) y(t)}{y(t)}=1-\eta\left(\frac{Y(t)}{y(t)}\right)^{\varphi}
$$

The objective of the representative household is to choose a consumption allocation over time in order to maximize the present value of lifetime utility:

$$
\max _{\{C(t), W(t)\}} U(C(t))=\int_{0}^{\infty} e^{-\rho t} \frac{C(t)^{1-\sigma}-1}{1-\sigma} d t
$$

subject to the flow budget constraint:

$$
\dot{W}(t)=(1-\tau(t))(\omega(t)+r(t) W(t))-C(t)
$$

where $\dot{W}(t)$ denotes the change of wealth over time, $C(t)$ is consumption at time $t, \rho>0$ is the household's subjective discount rate, $\sigma>0$ is the inverse of the intertemporal elasticity of substitution and $\tau$ is given by (9).

Making use of tax schedule (9) and the definition of income $y(t)$, the present value Hamiltonian for the representative agent's problem is given by:

$$
H(t)=e^{-\rho t} \frac{C(t)^{1-\sigma}-1}{1-\sigma}+q(t)\left[\eta\left(\frac{Y(t)}{\omega(t)+r(t) W(t)}\right)^{\varphi}(\omega(t)+r(t) W(t))-C(t)\right]
$$

where $q(t)$ denotes the co-state variable associated with the wealth accumulation equation (12). The optimality conditions for this intertemporal maximization problem are:

$$
q(t)=e^{-\rho t} C(t)^{-\sigma}
$$

and

$$
-\dot{\mathrm{q}}(\mathrm{t})=\eta(1-\varphi) \mathrm{q}(\mathrm{t}) \mathrm{r}(\mathrm{t})\left(\frac{\mathrm{Y}(\mathrm{t})}{\omega(\mathrm{t})+\mathrm{r}(\mathrm{t}) \mathrm{W}(\mathrm{t})}\right)^{\varphi}
$$

Combining (14) with (15) and using (10) yields the Euler equation:

$$
\frac{\dot{C}(t)}{C(t)}=\frac{\left(1-\tau_{m}\right) r(t)-\rho}{\sigma}
$$

which describes the evolution of consumption over time. Finally, we impose the standard transversality condition on the household's asset holdings:

$$
\lim _{t \rightarrow \infty} q(t) W(t)=0
$$




\section{ANGYRIDIS, TSINTZOS Public Investment and Debt}

\section{Equilibrium Conditions and the Balanced Growth Path}

An equilibrium allocation is defined as an allocation in which the firm maximizes profits, both private factors of production earn their marginal product (equations (2) and (3)), households maximize (11) subject to (12), and the budget constraint of the government (4) is satisfied. Furthermore, we consider a symmetric equilibrium such that $y(t)=Y(t)=Q(t)+$ $r(t) B(t)$ holds.

Combining equations (2)-(4), (7), (10), (12), (16) and either fiscal rule (5) or fiscal rule (6), allows us to derive an autonomous system of differential equations that completely describes the dynamics of the economy. For both fiscal rules, the growth rate of consumption is given by: ${ }^{4}$

$$
\frac{\dot{C}}{C}=\left(\frac{1}{\sigma}\right)\left[(1-\alpha)(1-\varphi) \eta A G^{\alpha} K^{-\alpha}\left(\frac{Y}{y}\right)^{\varphi}-\rho\right]
$$

With respect to fiscal rule FRO (equation (5)), the remainder of the dynamic system is as follows:

$$
\begin{gathered}
\frac{\dot{B}}{B}=A\left(\frac{G}{K}\right)^{\alpha}\left[\left(\psi_{1}-1\right)\left(\frac{K}{B}\right)+\eta\left(1-\alpha+\frac{K}{B}\right)\left(\frac{Y}{y}\right)^{\varphi}\right] \\
\frac{\dot{G}}{G}=\psi_{1} A\left(\frac{K}{G}\right)^{1-\alpha} \\
\frac{\dot{K}}{K}=\left(1-\psi_{1}\right) A\left(\frac{G}{K}\right)^{\alpha}-\frac{C}{K}
\end{gathered}
$$

On the other hand, the corresponding equations for the growth rates of public debt, public capital and private capital for fiscal rule FRT (equation (6)) are:

$$
\begin{gathered}
\frac{\dot{B}}{B}=A\left(\frac{G}{K}\right)^{\alpha}\left[\left(\alpha-1-\frac{K}{B}\right)\left(\left(\psi_{2}-1\right) \eta\left(\frac{Y}{y}\right)^{\varphi}-\psi_{2}\right)-\frac{K}{B}\right] \\
\frac{\dot{G}}{G}=\psi_{2} A\left(\frac{G}{K}\right)^{\alpha}\left[(1-\alpha)\left(\frac{B}{G}\right)+\frac{K}{G}\right]\left[1-\eta\left(\frac{Y}{y}\right)^{\varphi}\right] \\
\frac{\dot{K}}{K}=-\frac{C}{K}-(1-\alpha) A \psi_{2}\left(\frac{B}{K}\right)\left(\frac{G}{K}\right)^{\alpha}\left[1-\eta\left(\frac{Y}{y}\right)^{\varphi}\right]+A\left(\frac{G}{K}\right)^{\alpha}\left[1-\psi_{2}\left(1-\eta\left(\frac{Y}{y}\right)^{\varphi}\right)\right]
\end{gathered}
$$

\footnotetext{
${ }^{4}$ From this point on, the time argument $t$ will be omitted unless there is a possible ambiguity.
} 
A balanced growth path (BGP) is defined as a long-run equilibrium in which all endogenous variables grow at the same rate. Formally,

$$
\frac{\dot{C}}{C}=\frac{\dot{K}}{K}=\frac{\dot{G}}{G}=\frac{\dot{B}}{B}=\gamma
$$

where $\gamma>0$ denotes the economy's growth rate.

In order to analyze the dynamics of the model economy around a BGP, we define the following variables: $c \equiv C / K, b \equiv B / K$, and $g \equiv G / K$. Differentiating these variables with respect to time and using the fact that $y(t)=Y(t)$ yields a three-dimensional system of differential equations for each fiscal rule considered. In particular, when public investment is indexed to output (FRO), the dynamic system is given by:

$$
\begin{gathered}
\frac{\dot{c}}{c}=-\frac{\rho}{\sigma}+c+\left(\frac{1}{\sigma}\right)\left[\eta(1-\alpha)(1-\varphi)-\sigma\left(1-\psi_{1}\right)\right] A g^{\alpha} \\
\frac{\dot{b}}{b}=c-\left(1-(1-\alpha) \eta-\psi_{1}\right) A g^{\alpha}-\left(\frac{1}{b}\right)\left(1-\eta-\psi_{1}\right) A g^{\alpha} \\
\frac{\dot{g}}{g}=c+\psi_{1} A g^{\alpha-1}-\left(1-\psi_{1}\right) A g^{\alpha}
\end{gathered}
$$

On the other hand, when public investment is indexed to tax revenues (FRT), the dynamic system is as follows:

$$
\begin{gathered}
\frac{\dot{c}}{c}=-\frac{\rho}{\sigma}+c+\left(\frac{1}{\sigma}\right)\left(\eta(1-\alpha)(1-\varphi)-\sigma+\sigma(1-\eta) \psi_{2}[1+(1-\alpha) b]\right) A g^{\alpha} \\
\frac{\dot{b}}{b}=c-\left[1-(1-\alpha) \eta-(1-\eta) \psi_{2}(1+(1-\alpha)(1+b))\right] A g^{\alpha}-\left(\frac{1}{b}\right)(1-\eta)\left(1-\psi_{2}\right) A g^{\alpha} \\
\frac{\dot{g}}{g}=c+(1-\eta) \psi_{2}[1+(1-\alpha) b] \operatorname{Ag}^{\alpha-1}-\left[1-(1-\eta) \psi_{2}(1+(1-\alpha) b)\right] A g^{\alpha}
\end{gathered}
$$

The following proposition refers to the existence and uniqueness of the balanced growth path equilibrium for both fiscal policy rules under consideration.

Proposition 1 Under policy rule FRO, the dynamic system (25)-(27) has a steady state that is unique for any $\sigma>0$ and regardless of whether $b$ is positive or negative. Under policy rule FRT, the dynamic system (28)-(30) has a steady state that is unique if $\sigma>1-\varphi$ and $b>0$.

PROOF: See Appendix A.1. 


\section{ANGYRIDIS, TSINTZOS Public Investment and Debt}

For comparison purposes, we consider the flat tax specification that is commonly used in the related literature. In discussing this special case, we set $\varphi=0$ and $\eta=1-\tau$ in dynamic systems (25)-(27) and (28)-(30). Corollary 1 refers to the existence and uniqueness of a balanced growth path equilibrium for both expenditure rules under a flat tax system.

Corollary 1 With a flat tax, the dynamic system (25) - (27) under policy rule FRO has a steady state that is unique. On the other hand, under policy rule FRT and a flat tax rate, the dynamic system (28)-(30) has a steady state that is unique if $\sigma>1$.

PROOF: The values for the slope and level of the tax schedule required in order for tax schedule (9) to collapse to a flat tax rate are included in the range of values considered for these two parameters in Proposition 1. Therefore, the results of this proposition apply to this special case as well.

Along the BGP, if $r<\gamma$, then the economy is dynamically inefficient under both fiscal rules, implying that the government can play a Ponzi game. Therefore, we only consider the case $r>\gamma$. Corollary 2 determines the parametric restriction required for the allocation in the long-run equilibrium to satisfy this property.

Corollary 2 If $\sigma>(1-\varphi) \eta$, then for both fiscal rules along the BGP $r>\gamma$.

PROOF: Recall that Euler equation (18) is common for both fiscal rules. Evaluating this optimality condition along the BGP and given that we would like to show that $r>\gamma$, it follows that

$$
r\left[1-\frac{(1-\varphi) \eta}{\sigma}\right]>-\frac{\rho}{\sigma}
$$

A sufficient condition for this inequality to hold is that $\sigma>(1-\varphi) \eta$.

Furthermore, we note that the two fiscal rules have different implications in terms of the stance of the government as a debtor or a creditor. Corollary 3 refers to this property of the long-run equilibrium under either rule. 
Corollary 3 Assume that $\sigma>1-\varphi$. Under the FRO rule, the government can be either a creditor or a debtor along the BGP. In contrast, the government can only be a debtor along the BGP in the case of the FRT rule.

PROOF: Evaluating (4) along the BGP under the FRO rule and rearranging, yields

$$
(\eta r-\gamma) \frac{B}{Q}=1-\psi_{1}-\eta
$$

Substituting for $r$ and $\gamma$ into $\eta r-\gamma$ yields:

$$
\eta r-\gamma=\eta(1-\alpha) A g^{\alpha}\left[\frac{\sigma-(1-\varphi)}{\sigma}\right]+\frac{\rho}{\sigma}
$$

Given that $\sigma>1-\varphi$, it follows that $\eta r>\gamma$. Hence, $B \gtrless 0$ when $\psi_{1}+\eta \lessgtr 1$. Therefore, in this case, the government can be either a creditor or a debtor in the long-run equilibrium. Similarly, evaluating (4) along the BGP under the FRT rule implies that:

$$
\left[r\left(\eta+\psi_{2}(1-\eta)\right)-\gamma\right] \frac{B}{Q}=\left(1-\psi_{2}\right)(1-\eta)
$$

Substituting for $r$ and $\gamma$ into the term inside the brackets yields:

$$
r\left(\eta+\psi_{2}(1-\eta)\right)-\gamma=(1-\alpha) A g^{\alpha}\left[\frac{\eta(\sigma-(1-\varphi))+\sigma \psi_{2}(1-\eta)}{\sigma}\right]+\frac{\rho}{\sigma}
$$

Once again, given that $\sigma>1-\varphi$, it is the case that $r\left(\eta+\psi_{2}(1-\eta)\right)>\gamma$. Since the righthand side of the above expression is positive, it follows that $B>0$. Thus, in contrast to the FRO rule, the government is always a debtor under the FRT rule.

Note that, given $0<\eta<1$, the parametric condition $\sigma>(1-\varphi) \eta$ in Corollary 2 is less stringent than the condition $\sigma>1-\varphi$ required for both rules in Corollary 3. Furthermore, it satisfies the parametric condition required for the FRT rule in Proposition 1. On the other hand, the parametric condition in Corollary 2 imposes a lower bound on the value of the inverse of the intertemporal elasticity of substitution required for the FRO rule in Proposition $1(\sigma>0)$. For these reasons, we will assume for the remainder of our analysis that $\sigma>1-$ $\varphi$. 


\section{ANGYRIDIS, TSINTZOS Public Investment and Debt}

\section{Dynamic Analysis}

In this section, we discuss the possibility of indeterminacy in the parametric domain considered in Proposition 1 and Corollary 2. A steady state or balanced growth path equilibrium is said to be indeterminate if there exists a non-degenerate interval $\Omega$ such that for every initial condition of the predetermined variables $b(0)$ and $g(0)$ and the jump variable $c(0) \in \Omega$, the economy converges to the same long-run equilibrium. In contrast, when there is a unique transition path to the steady state or balanced growth path equilibrium, then we have determinacy.

The concept of indeterminacy implies the existence of infinite transition paths converging to the same long-run equilibrium. This implies that in order to obtain a determinate long-run equilibrium we need to establish the parametric conditions under which there exists a unique saddle path. For this to be the case, the number of stable (negative) eigenvalues should be equal to the number of predetermined variables. In our model, we have two predetermined variables, $b(t)$ and $g(t)$, and one jump variable, $c(t)$. Therefore, for the long-run equilibrium under either fiscal policy rule established in Proposition 1 to be determinate we require that we have two stable (negative) eigenvalues. In contrast, the presence of three negative eigenvalues gives rise to indeterminacy. In all other cases, the long-run equilibrium is unstable in the sense that a perturbation from the BGP will cause the economy to permanently deviate from it.

Proposition 2 below considers the possibility of indeterminacy for the fiscal policy rule under which public investment expenditure is indexed to output (FRO).

Proposition 2 Consider the parametric domain established in Proposition 1 and Corollary 2 for policy rule FRO. Within this domain, dynamic system (25) - (27) has one negative and one positive eigenvalue in the neighborhood of its steady state. If $\psi_{1}+\eta<1$, then the third eigenvalue is positive and the BGP is unstable. On the other hand, when $\psi_{1}+\eta \geq 1$, the third eigenvalue is negative and we have determinacy.

\section{PROOF: See Appendix A.2.}

Note that an implication of Proposition 2 is that, when $\psi_{1}+\eta \geq 1$, the long-run equilibrium is stable in the saddle point sense. Furthermore, from Corollary 3, it follows that the government in this case is a creditor. On the other hand, when $\psi_{1}+\eta<1$ the $\mathrm{BGP}$ is unstable and, as it has been shown in Corollary 3 , the government in this case is a debtor. 
Next, we turn our attention to the policy rule that indexes public investment expenditure to tax revenues (FRT). Proposition 3 below considers the potential presence of indeterminacy or instability in this case.

Proposition 3 Consider the parametric domain established in Proposition 1 and Corollary 2 for policy rule FRT. Within the specific parametric domain, dynamic system (28) - (30) exhibits either instability or indeterminacy.

\section{PROOF: See Appendix A.3.}

\section{Discussion}

To understand the intuition behind our results regarding the potential presence of indeterminacy, assume that starting from an initial position for the economy households form optimistic beliefs about future economic activity. These beliefs manifest themselves by a higher expected after-tax rate of return on their wealth. Acting upon their rosy expectations about the future, households begin to consume less and save more today.

What differentiates our framework from other studies in the related literature is the presence of a second asset that households can invest in apart from private capital: bonds issued by the government. In making their investment decisions, households internalize the fact that an expansion in economic activity that is consistent with their optimistic beliefs will allow the government to allocate more resources towards increasing the stock of public capital. For this reason, households prefer to invest more in bonds rather than capital.

An implication of this is that, following the agents' formation of optimistic beliefs, the stock of public capital rises faster than the stock of private capital in the long run. As a consequence, the public-to-private capital ratio increases causing the economy's long-run growth rate to rise (see equation (18)), while the debt-to-private capital ratio rises as well (see equation (A.3) in the case of the FRT rule). ${ }^{5}$ Furthermore, the increase in $g$ causes the aftertax rate of return on wealth to rise. Hence, in this case, the agents' initial optimistic expectations are validated and the economy's expected transition path becomes a selffulfilling equilibrium.

${ }^{5}$ A similar positive relation between the two ratios holds in the case of the FRO rule when the government is a creditor. Combining (25) and (26) after having been evaluated along the BGP and totally differentiating yields:

$$
\frac{d b}{d g}=\frac{\alpha \rho}{\left(1-\eta-\psi_{1}\right) \sigma A} b^{2} g^{-(1+\alpha)},
$$

which is positive if the government is a debtor $\left(\psi_{1}<1-\eta\right)$ and negative if it is a creditor $\left(\psi_{1}>1-\right.$ $\eta)$. 


\section{ANGYRIDIS, TSINTZOS Public Investment and Debt}

A requirement for this case to materialize is that the government supplies bonds that are available for purchase by the households. In other words, the government is a debtor. If the government is a creditor instead, then households acting upon their optimistic beliefs will invest in private capital. In this case, the stock of public capital does not rise faster that the stock of private capital. As a consequence, the after-tax rate of return on wealth does not increase in the long run and the rosy expectations of consumers do not become self-fulfilled. This is the reason why indeterminacy can possibly occur only with a debtor government.

On the other hand, the presence of a creditor government leads to determinacy in our model. As it was shown in Corollary 3, this can only occur if the government follows the FRO rule. Following Proposition 2, the condition for indeterminacy requires that the fraction of output allocated to public investment is larger than the average tax rate: $\psi_{1} \geq 1-\eta$. The condition for determinacy is a natural one: for every dollar raised in revenues by the government, a larger fraction can be allocated towards public investment. In other words, the government can afford to allocate more resources to public investment per dollar raised as revenue relative to a debtor government which has to use a portion of its revenues to service its debt.

As it is stated in Propositions 2 and 3, the potential presence of instability also arises in our model. In this case, a perturbation from the BGP causes the economy to permanently deviate from it. In terms of the dynamics of the economy, instability leads to infeasible solutions; see, for example, Greiner and Semmler (1996). ${ }^{6}$ As in the case of indeterminacy, the choice of the fiscal stance made by the government can prevent these outcomes from occurring. A creditor government following the FRO rule never causes the economy to become unstable. On the other hand, an economy with a debtor government following the same fiscal rule as in the previous case is always unstable.

\section{Quantitative Analysis}

In this section, we provide a numerical illustration of the theoretical results derived in the previous sections for the two fiscal rules. The model is calibrated to the U.S. economy. The objective of our parameterization is to closely match the historical post-WWII averages of three ratios: (i) the debt-to-private capital ratio $(b)$, (ii) the public-to-private capital ratio $(g)$, and (iii) the consumption-to-private capital ratio $(c)$.

Using data that cover the period 1946-2006, Atolia et al. (2011) determine that the ratio of public-to-private capital is roughly equal to 0.5070 . Based on data obtained from the National

\footnotetext{
${ }^{6}$ These solutions include, for instance, the violation of transversality conditions, corner solutions with economically nonsensible values (e.g. zero consumption) or trajectories that are permanently gyrating around the BGP with no tendency to converge back to it.
} 
Income and Product Accounts provided by the Bureau of Economic Analysis (BEA) that cover the period 1961-2010, we calculate the average consumption-to-output ratio to be 0.6577. Atolia et al. (2011) calculate the ratio of private capital-to-output to be 2.17. Combining these two figures implies that in the long-run equilibrium the consumption-toprivate capital ratio is equal to 0.3031 . Finally, regarding the target value of the debt-toprivate capital ratio, we use data from the Organization of Economic Cooperation and Development (OECD) covering the period 1973-2015 to obtain an average value for the federal debt held by the public as a percentage of GDP of 0.4086. Combining this figure with the estimate of the private capital-to-output ratio provided by Atolia et al. (2011) yields a value of $b$ in the long-run equilibrium of 0.1883 .

In growth and business cycle theory, the intertemporal elasticity of substitution represents perhaps the most crucial parameter since it captures the willingness of households to substitute consumption between periods in response to changes in the after-tax interest rate. In order to assign a value to this parameter in our case, we follow Havranek et al. (2015) who use meta-regression analysis to obtain estimates of this elasticity for a large panel of countries. Based on 1429 published studies for the United States on this topic, these authors obtain an estimate of this elasticity of 0.594 with a standard error of 0.036 . For this reason, we set the value of the inverse of this elasticity $(\sigma)$ equal to 1.68 .

In terms of the coefficients in policy rules (5) and (6), we use annual data for the gross domestic product, current tax receipts and gross government investment of the U.S. economy. This data covers the period 1969-2014 and is also obtained from the National Income and Product Accounts. The average gross domestic product during the sample period is $\$ 7,456.6$ billion, while the average tax receipts and gross government investment are $\$ 1,449.0$ and $\$ 310.6$ billion, respectively. Based on these values, we set $\psi_{1}=0.04$ and $\psi_{2}=0.21$. In other words, gross government investment is on average equal to $4 \%$ of GDP, or alternatively, $21 \%$ of tax revenues.

Regarding the elasticity of output with respect to public capital, we follow Atolia et al. (2011) and set $\alpha$ equal to 0.10 . With respect to the parameters of the progressive income tax schedule (9), we set $\eta=0.837$ and $\varphi=0.05$. Both values are close to the ones estimated by Chen and Guo (2013b) using U.S. federal individual income tax data over the period 19662005. The total factor productivity parameter $A$ varies between the two fiscal rules. For the FRO rule we set it equal to 0.4002 , while for the FRT rule we assign a value of 0.3668 . Finally, considering a value for $\rho$ of 0.20 , the above parameterization allows us to obtain values for the $b, g$ and $c$ ratios that closely match their average postwar values for both rules. Table 1 below reports the values of the three ratios obtained from the data and the values obtained from solving for the BGP equilibrium of each fiscal rule. 


\section{ANGYRIDIS, TSINTZOS Public Investment and Debt}

Table 1: Ratios $\boldsymbol{b}, \boldsymbol{g}$ and $\boldsymbol{c}$

\begin{tabular}{|c||c|c|c|}
\hline Ratio & Data & FRO & FRT \\
\hline \hline$b$ & 0.1883 & 0.1824 & 0.1825 \\
\hline$g$ & 0.5070 & 0.5070 & 0.5070 \\
\hline$c$ & 0.3031 & 0.3022 & 0.3021 \\
\hline
\end{tabular}

Note that the above parameterization of the model satisfies the restrictions stated in Proposition 1 and Corollary 2. Furthermore, in all numerical examples performed, we verify that along the BGP it is the case that the public-to-private capital ratio exceeds its threshold level $\tilde{g}$ and that $r>g$.

Regarding the FRO fiscal rule, our parameterization implies that $\psi_{1}+\eta=0.877<1$. This is consistent with Corollary 3 since we require the government to be a debtor along the BGP. It follows from Proposition 2 that the dynamic system (25) - (27) is unstable. This is confirmed numerically since there is one negative eigenvalue (-0.0869) and two positive ones (0.9638 and 1.3826). Regarding the FRT fiscal rule, recall that according to Proposition 3 the dynamic system (28) - (30) may exhibit either instability or indeterminacy. Based on our parameterization, there is one negative eigenvalue (-0.0788) and two positive ones $(0.9429$ and 1.3585). Hence, it is confirmed that the long-run equilibrium is unstable.

As a numerical example to illustrate the robustness of our results, we reconsider the FRO rule by keeping $\eta$ fixed at 0.837 and setting $\psi_{1}$ equal to 0.21 . This ensures that $\psi_{1}+\eta>1$, which from Corollary 3 implies that the government is a creditor instead of a debtor. Hence, in contrast to the case of using the calibrated value of $\psi_{1}$, the dynamic system (25) - (27) should be saddle-path stable. Consistent with Proposition 2, in this case there is one positive eigenvalue (0.9903) and two negative ones (-3.3317 and -0.0474). Finally, in agreement with Corollary 3 , the government is a creditor with $b=-0.0767<0$ along the balanced growth path.

Next, we examine the sensitivity of our results with respect to the value of the intertemporal elasticity of substitution. For each rule, we use our calibrated parameters and vary only the value of $\sigma$. Tables 2 and 3 below report the $b, g$ and $c$ ratios, as well as the corresponding eigenvalues for the FRO rule and the FRT rule, respectively. Note that in both cases, we consider values for the inverse of the intertemporal elasticity of substitution that satisfy the condition $\sigma>1-\varphi$.

The relationship between two of the eigenvalues and parameter $\sigma$ is qualitatively similar for both rules. Eigenvalue $\lambda_{1}$ lies in the negative quadrant and is strictly increasing with respect to $\sigma$. In contrast, eigenvalue $\lambda_{3}$ takes values in the positive quadrant but it is also strictly increasing. On the other hand, the behavior of eigenvalue $\lambda_{2}$ differs between the two 
Review of Economic Analysis 10 (2018) 121-150

Table 2: FRO Sensitivity analysis with respect to $\boldsymbol{\sigma}(\boldsymbol{b}>\mathbf{0})$

\begin{tabular}{|c|c|c|c|c|c|c|}
\hline$\sigma$ & $b$ & $g$ & $c$ & $\lambda_{1}$ & $\lambda_{2}$ & $\lambda_{3}$ \\
\hline \hline 0.96 & 0.2042 & 0.2650 & 0.2835 & -0.2845 & 0.9779 & 1.0337 \\
\hline 1 & 0.2027 & 0.2730 & 0.2859 & -0.2687 & 0.9752 & 1.0518 \\
\hline 2 & 0.1848 & 0.4568 & 0.3228 & -0.0971 & 0.9555 & 1.3333 \\
\hline 5 & 0.1731 & 0.9400 & 0.3649 & -0.0230 & 0.9662 & 1.6334 \\
\hline 10 & 0.1688 & 1.6623 & 0.3941 & -0.0075 & 0.9777 & 1.8204 \\
\hline
\end{tabular}

Table 3: FRT Sensitivity analysis with respect to $\boldsymbol{\sigma}(\boldsymbol{b}>\mathbf{0})$

\begin{tabular}{|c|c|c|c|c|c|c|}
\hline$\sigma$ & $b$ & $g$ & $c$ & $\lambda_{1}$ & $\lambda_{2}$ & $\lambda_{3}$ \\
\hline \hline 0.96 & 0.1923 & 0.3502 & 0.2791 & -0.1691 & 0.9413 & 1.1996 \\
\hline 1 & 0.1915 & 0.3595 & 0.2809 & -0.1603 & 0.9416 & 1.2107 \\
\hline 2 & 0.1802 & 0.5721 & 0.3090 & -0.0615 & 0.9441 & 1.4074 \\
\hline 5 & 0.1720 & 1.1197 & 0.3432 & -0.0157 & 0.9572 & 1.6429 \\
\hline 10 & 0.1686 & 1.9239 & 0.3681 & -0.0053 & 0.9677 & 1.7997 \\
\hline
\end{tabular}

rules. In the case of the FRO rule, it is U-shaped and lies in the positive quadrant, while in the case of FRT rule it increases as the intertemporal elasticity of substitution falls. Regardless of these differences, the results reported in Tables 2 and 3 are consistent with Proposition 3: a debtor government results in a long-run equilibrium that is unstable for both rules.

For completeness, we consider also the case of a creditor government which, according to Corollary 3, applies only to the case of the FRO rule. Keeping our benchmark parameterization unaltered with the exception of $\psi_{1}$, which is set equal to 0.20 , we solve for the BGP and the corresponding eigenvalues for the same values of $\sigma$ as in Tables 2 and 3. Table 4 below summarizes these calculations.

Comparing the last three columns with those in Table 2 shows that the fiscal stance of the government has no qualitative effect on eigenvalues $\lambda_{1}$ and $\lambda_{2}$. On the other hand, $\lambda_{3}$ now takes values in the negative quadrant instead of the positive one, while it is strictly increasing with $\sigma$ instead of decreasing.

The above sensitivity analysis with respect to the intertemporal elasticity of substitution shows that its value is important only for the existence of a unique BGP and to ensure that the long-run equilibrium is dynamically efficient. However, it appears to play no role in terms of making instability or indeterminacy more or less likely. The latter depends only on whether the government is a debtor or a creditor. Comparing Tables 2 and 3, as $\sigma$ increases, then for both rules $b$ falls, $g$ rises and $c$ increases. As the public-to-private capital ratio increases, equation (3) implies that the interest rate increases as well in both cases. The only difference 


\section{ANGYRIDIS, TSINTZOS Public Investment and Debt}

Table 4: FRO Sensitivity analysis with respect to $\boldsymbol{\sigma}(\boldsymbol{b}<\mathbf{0})$

\begin{tabular}{|c|c|c|c|c|c|c|}
\hline$\sigma$ & $b$ & $g$ & $c$ & $\lambda_{1}$ & $\lambda_{2}$ & $\lambda_{3}$ \\
\hline \hline 0.96 & -0.0694 & 0.9095 & 0.2300 & -0.1190 & 0.9979 & -3.0482 \\
\hline 1 & -0.0685 & 0.9400 & 0.2336 & -0.1117 & 0.9968 & -3.1406 \\
\hline 2 & -0.0585 & 1.6623 & 0.2862 & -0.0369 & 0.9892 & -4.5595 \\
\hline 5 & -0.0530 & 3.6205 & 0.3390 & -0.0081 & 0.9918 & -5.9941 \\
\hline 10 & -0.0512 & 6.6233 & 0.3722 & -0.0025 & 0.9947 & -6.8324 \\
\hline
\end{tabular}

is that for the FRO rule the growth rate rises (from 5.3\% to $10.1 \%$ ), while for the FRT rule it falls (from $3.8 \%$ to $0.8 \%$ ). For both rules, the growth rate is determined by equation (18). Given that $g$ rises with $\sigma$, it must be the case that the rate of increase in the public-to-private capital ratio is sufficiently lower under the FRT rule compared to the FRO rule, thus, causing a reduction in the growth rate instead of an increase.

Finally, we explore numerically the robustness of our results by allowing the depreciation rates of private and public capital to be strictly positive instead of being zero. The version of the model that includes the two depreciation rates and is used in our dynamic analysis is presented in Appendix B. Relative to the our initial calibration scheme, we leave the values of $\sigma, \psi_{1}$ and $\psi_{2}$ unchanged. The remaining parameters are appropriately adjusted to ensure that the model closely matches the $b, g$ and $c$ ratios for both rules.

In particular, we adopt the following parameterization for the FRO rule: $\alpha=0.3, \rho=$ $0.12, \varphi=0.25, \eta=0.9$ and $A=0.5188$. In addition, we set the depreciation rate of private capital, $\delta_{K}$, equal to 0.11 , while the depreciation rate of public capital, $\delta_{G}$, is assumed to be equal to 0.03 . Similarly, we use the following parameter values for the FRT rule: $\alpha=0.26$, $\rho=0.12, \varphi=0.21, \eta=0.8795, A=0.5068, \delta_{K}=0.11$ and $\delta_{G}=0.01$. Note that the values of the depreciation rates are close to the ones adopted by Atolia et al. (2011). Table 5 below reports the values of the three ratios obtained from the data and the values obtained from solving for the BGP equilibrium of each fiscal rule.

In the spirit of Proposition 2, since the government is a debtor in the long-run equilibrium, we expect the corresponding dynamic system to be unstable under the FRO rule. This expectation is validated since there is only one negative eigenvalue (-0.1413) and two positive ones (0.8248 and 0.9109). Regarding the FRT rule, there are also two positive eigenvalues (0.8212 and 0.9340) and one negative (-0.0982). Hence, the BGP exhibits instability in this case as well. This result is consistent with the predictions of Proposition $3 .^{7}$

\footnotetext{
${ }^{7}$ The numerical results reported in this section, as well as an extensive sensitivity analysis with respect to our parameterizations, are available from the authors upon request.
} 
Review of Economic Analysis 10 (2018) 121-150

Table 5: Ratios $\boldsymbol{b}, \boldsymbol{g}$ and $\boldsymbol{c}$ with depreciation rates

\begin{tabular}{|c||c|c|c|}
\hline Ratio & Data & FRO & FRT \\
\hline \hline$b$ & 0.1883 & 0.1803 & 0.1977 \\
\hline$g$ & 0.5070 & 0.5070 & 0.5070 \\
\hline$c$ & 0.3031 & 0.3080 & 0.3031 \\
\hline
\end{tabular}

\section{Conclusions}

We consider an endogenous growth model with public capital, progressive income taxation and government debt. We derive analytically the necessary and sufficient parametric space that ensures uniqueness of equilibrium under two government expenditure rules: a rule that indexes public investment to output and a rule that indexes productive spending to tax revenues.

It is shown that the transitional dynamics of the economy crucially depend on whether the government is a debtor or a creditor in the long-run equilibrium. In particular, when the government is a creditor, the long-run equilibrium is always locally determinate. Based on Corollary 3, the government can be a creditor only in the case that it indexes public investment expenditure to output. On the other hand, a government can be a debtor under either fiscal rule. Public indebtedness gives rise to a rich set of possible dynamics. If a debtor government indexes productive spending to output, then the long-run equilibrium exhibits instability. Alternatively, if the government indexes public investment expenditure to tax revenues, then the balanced growth path equilibrium can be either locally indeterminate or unstable. Hence, overall, public indebtedness leads to indeterminacy or instability with the latter outcome occurring with a higher likelihood.

In addition, the degree of progressivity of the income tax schedule does not appear to influence the possibility of the model exhibiting indeterminacy or not. Finally, in terms of implications regarding policy design, our results suggest that a government should prefer a fiscal rule that ties public investment to output, rather than tax revenues, and be a creditor rather than a debtor. Otherwise, the economy will be susceptible to either belief-driven aggregate fluctuations or unstable dynamics.

Motivated by the substantial accumulation of sovereign debt during the recent global economic downturn, Woo and Kumar (2015) revisit the relationship between public indebtedness and growth. In particular, they provide concrete evidence on the significant adverse impact of initial high public debt on subsequent growth over the next 5-20 years (or longer) based on a large panel of advanced and emerging economies for the period 19702008. In obtaining this result, the authors apply a large variety of econometric techniques, control for a substantial number of variables that potentially affect long-term growth and perform a battery of robustness checks. They also detect the presence of a nonlinearity with 


\section{ANGYRIDIS, TSINTZOS Public Investment and Debt}

higher levels of initial debt above $90 \%$ of GDP having more significantly negative effects on subsequent growth. The policy implications of our model are consistent with the robust empirical findings of Woo and Kumar (2015). Furthermore, these implications concur with the results of Fatás and Mihov (2003) based on data for 91 countries that excessive discretionary fiscal policy leading to the accumulation of debt induces significant macroeconomic instability and lowers economic growth.

The present framework can be extended in several ways. A possibility involves introducing labor-leisure choice as in Chen and Guo (2013b). Building on the model in Chen and Guo (2013a), these authors show that their model economy exhibits indeterminacy and sunspots if the equilibrium after-tax wage-hours locus is positively sloped and steeper than the household's labor supply curve. Another possible extension involves examining indeterminacy in the context of a two sector model as in Chang et al. (2015). These authors examine the interaction between the composition of government expenditures and equilibrium indeterminacy in a two sector model with productive externalities in investment. They find that the economy is more susceptible to indeterminacy and sunspots when the output fraction of government purchases of investment goods is relatively small. We are planning to pursue these extensions in future research.

\section{Appendix A}

\section{A.1 Proof of Proposition 1}

Recall that based on the model's specification, $0<\alpha<1 / 2,0<\eta<1, \sigma>0, \rho>0$, $A>0,0<\varphi<1,0<\psi_{1}<1$, and $0<\psi_{2}<1$. For both policy rules, we constrain ourselves to a nonnegative long-run growth rate: $\gamma \geq 0$. Evaluating Euler equation (18) along the BGP, it follows that the public capital-to-private capital ratio should satisfy:

$$
g \geq\left[\frac{\rho}{(1-\alpha)(1-\varphi) \eta A}\right]^{\frac{1}{\alpha}} \equiv \tilde{g}>0
$$

Note that this threshold level for $g$ is common for both expenditure rules.

We next turn to showing existence and uniqueness of a BGP. First, consider the policy rule that indexes public investment expenditure to output (FRO). Setting (25) equal to zero, solving for $c$ and inserting it into (27) with $\dot{g} / g=0$ yields:

$$
f(g)=\frac{\rho}{\sigma}-\frac{1}{\sigma}[\eta(1-\alpha)(1-\varphi)] A g^{\alpha}+\psi_{1} A g^{\alpha-1}=0
$$


It follows that for any $g \in[\tilde{g},+\infty)$ :

$$
f^{\prime}(g)=-(1-\alpha)\left(\frac{\alpha}{\sigma} \eta(1-\varphi)+\frac{\psi_{1}}{g}\right) A g^{\alpha-1}<0
$$

Furthermore, it can be easily seen that $\lim _{g \rightarrow 0} f(g)=+\infty$ and $\lim _{g \rightarrow+\infty} f(g)=-\infty$. Hence, function $f(g)$ is continuously differentiable and monotonically decreasing for $g \in[\tilde{g},+\infty)$. This implies that there exists a unique positive $\hat{g}$ that solves (A.1). Given $\hat{g}$, we can solve for $\hat{c}$ from equation (25) and, then, for $\hat{b}$ from equation (26) after setting $\dot{b} / b=0$. Thus, a unique BGP exists.

Next, consider the policy rule that indexes public investment expenditure to tax revenues (FRT). Setting (28) equal to zero, solving for $c$ and substituting it into (30) with $\dot{g} / g=0$ yields:

$f(g, b)=\frac{\rho}{\sigma}-\frac{1}{\sigma}[\eta(1-\alpha)(1-\varphi)] A g^{\alpha}+(1-\eta) \psi_{2}[1+(1-\alpha) b] A g^{\alpha-1}=0$

Notice that for a given public-to-private capital ratio $g, f(\cdot)$ is a linear function of the public debt-to-private capital ratio. This is in contrast to the previous case where function $f(\cdot)$ is independent of $b$.

In addition, evaluating (29) along the BGP and substituting for $c$ from (28) we obtain:

$$
b^{-1}=\frac{\rho / \sigma}{(1-\eta)\left(1-\psi_{2}\right) A g^{\alpha}}+\frac{(1-\alpha) \psi_{2}}{1-\psi_{2}}+\frac{\eta(1-\alpha)}{(1-\eta)\left(1-\psi_{2}\right)}\left[1-\frac{1-\varphi}{\sigma}\right]
$$

This expression implies that the public-to-private capital ratio is positively related to the debt-to-private capital ratio. Intuitively, government bonds are an asset from the perspective of the household. As debt issue by the government increases, household's wealth increases as well. However, the household's wealth is a source of revenue for the government. It follows that an increase in wealth leads to an increase in the tax revenues collected by the government. Under fiscal rule FRT, public investment is equal to a fraction of tax revenues. Hence, the rise in revenues causes public investment to increase. This leads to a higher accumulation of public capital causing the public-to-private capital ratio to increase.

Assuming that $b>0$, the sign of equation (A.3) clearly depends on the sign of the last term. It follows that a sufficient condition for the public debt-to-private capital ratio to be positive for any $g \in[\tilde{g},+\infty)$ is that $\sigma>1-\varphi$.

Differentiating (A.2) with respect to $g$ taking $b$ as given yields: 
ANGYRIDIS, TSINTZOS Public Investment and Debt

$$
\frac{\partial f(g, b)}{\partial g}=-(1-\alpha)\left(\left(\frac{1}{\sigma}\right) \alpha \eta(1-\varphi)+(1-\eta)[1+(1-\alpha) b]\left(\frac{\psi_{2}}{g}\right)\right) A g^{\alpha-1}<0
$$

Furthermore, it can be easily seen that $\lim _{g \rightarrow 0} f(g, b)=+\infty$ and $\lim _{g \rightarrow+\infty} f(g, b)=-\infty$. These results imply that there exists a unique positive pair $(\hat{g}, \hat{b})$ that solves (A.2) and (A.3). Given $\hat{g}$ and $\hat{b}$, we can solve for $\hat{c}$ from equation (28). Thus, a unique BGP exists.

\section{A.2 Proof of Proposition 2}

The Jacobian of system (25) - (27) is

$$
J=\left[\begin{array}{ccc}
1 & 0 & \frac{\left[\eta(1-\alpha)(1-\varphi)-\sigma\left(1-\psi_{1}\right)\right] \alpha A g^{\alpha-1}}{\sigma} \\
1 & \frac{\left(1-\eta-\psi_{1}\right) A g^{\alpha}}{b^{2}} & -\left(1-(1-\alpha) \eta-\psi_{1}\right) \alpha A g^{\alpha-1}-\frac{\left(1-\eta-\psi_{1}\right) \alpha A g^{\alpha-1}}{b} \\
1 & 0 & -(1-\alpha) \psi_{1} A g^{\alpha-2}-\alpha\left(1-\psi_{1}\right) A g^{\alpha-1}
\end{array}\right]
$$

Let $\operatorname{Tr}(J)$ and $\operatorname{Det}(J)$ denote the trace and determinant of the Jacobian matrix, respectively. The characteristic polynomial is given by:

$$
f(\lambda)=-\lambda^{3}+\operatorname{Tr}(J) \lambda^{2}+A g^{\alpha-2} \Gamma \lambda+\operatorname{Det}(J)=0
$$

where

$$
\begin{aligned}
& \operatorname{Tr}(J)=1-\left[(1-\alpha) \psi_{1}+\alpha\left(1-\psi_{1}\right) g\right] A g^{\alpha-2}+\frac{\left(1-\eta-\psi_{1}\right) A g^{\alpha}}{b^{2}} \\
& \operatorname{Det}(J)=-\frac{(1-\alpha)\left(1-\eta-\psi_{1}\right)\left(\alpha \eta(1-\varphi) g+\sigma \psi_{1}\right)}{\sigma b^{2}} A^{2} g^{-2(1-\alpha)}
\end{aligned}
$$

and

$\Gamma \equiv \frac{(1-\alpha)\left[\sigma \psi_{1}+\alpha \eta(1-\varphi) g\right]}{\sigma}-\frac{\left(1-\eta-\psi_{1}\right)\left[g^{2}-\left((1-\alpha) \psi_{1}+\alpha\left(1-\psi_{1}\right) g\right) A g^{\alpha}\right]}{b^{2}}$

The corresponding eigenvalues are: 
Review of Economic Analysis 10 (2018) 121-150

$$
\lambda_{1}=\frac{\left(1-\eta-\psi_{1}\right) A g^{\alpha}}{b^{2}}
$$

and

$$
\lambda_{2,3}=\frac{\sigma\left[g^{2}-\left((1-\alpha) \psi_{1}+\alpha\left(1-\psi_{1}\right) g\right) A g^{\alpha}\right] \pm \Delta}{2 \sigma g^{2}}
$$

where

$$
\Delta \equiv \sqrt{\sigma\left(4(1-\alpha) A g^{\alpha+2}\left(\sigma \psi_{1}+\alpha \eta(1-\varphi) g\right)+\left[g^{2}-\left((1-\alpha) \psi_{1}+\alpha\left(1-\psi_{1}\right) g\right) A g^{\alpha}\right]^{2}\right)}
$$

Consider the product of $\lambda_{2}$ and $\lambda_{3}$ :

$$
\lambda_{2} \lambda_{3}=-\frac{(1-\alpha)\left[\sigma \psi_{1}+\alpha \eta(1-\varphi) g\right]}{\sigma} A g^{\alpha-2}<0
$$

It follows that there is always one negative and one positive eigenvalue. Hence, whether there is determinacy or not depends on the sign of $\lambda_{1}$. If $\psi_{1}+\eta<1$, then this eigenvalue is positive and the BGP is unstable. In contrast, when $\psi_{1}+\eta \geq 1$, then $\lambda_{1}<0$ and we have determinacy.

\section{A.3 Proof of Proposition 3}

The Jacobian of system (28) - (30) is

$$
J=\left[\begin{array}{lll}
a_{11} & a_{12} & a_{13} \\
a_{21} & a_{22} & a_{23} \\
a_{31} & a_{32} & a_{33}
\end{array}\right]
$$

where

$$
\begin{gathered}
a_{11}=a_{21}=a_{31}=1 \\
a_{12}=(1-\alpha)(1-\eta) \psi_{2} A g^{\alpha} \\
a_{13}=\left(\frac{1}{\sigma}\right)\left(\eta(1-\alpha)(1-\varphi)-\sigma+\sigma(1-\eta) \psi_{2}[1+(1-\alpha) b]\right) \alpha A g^{\alpha-1}
\end{gathered}
$$


ANGYRIDIS, TSINTZOS Public Investment and Debt

$$
\begin{gathered}
a_{22}=\left[(1-\alpha) \psi_{2}+\left(\frac{1}{b^{2}}\right)\left(1-\psi_{2}\right)\right](1-\eta) A g^{\alpha} \\
a_{23}=-\left[\left[1-(1-\alpha) \eta-(1-\eta) \psi_{2}(1+(1-\alpha)(1+b))\right]+\left(\frac{1}{b}\right)(1-\eta)\left(1-\psi_{2}\right)\right] \alpha A g^{\alpha-1} \\
a_{32}=(1-\alpha)(1-\eta) \psi_{2} A g^{\alpha}\left(1+\frac{1}{g}\right)
\end{gathered}
$$

and

$$
a_{33}=-(1-\alpha)(1-\eta) \psi_{2}[1+(1-\alpha) b] A g^{\alpha-2}-\alpha\left[1-(1-\eta) \psi_{2}(1+(1-\alpha) b)\right] A g^{\alpha-1}
$$

Let $\operatorname{Tr}(J)$ and $\operatorname{Det}(J)$ denote the trace and determinant of the Jacobian matrix, respectively. The characteristic polynomial is given by:

$$
f(\lambda)=-\lambda^{3}+\operatorname{Tr}(J) \lambda^{2}+\mathrm{Z} \lambda+\operatorname{Det}(J)=0
$$

where

$$
\begin{gathered}
\operatorname{Tr}(J)=1+a_{22}+a_{33} \\
\operatorname{Det}(J)=a_{13}\left(a_{32}-a_{22}\right)+a_{12}\left(a_{23}-a_{33}\right)+a_{22} a_{33}-a_{23} a_{32}
\end{gathered}
$$

and

$$
\mathrm{Z} \equiv a_{12}+a_{13}-a_{22}+a_{23} a_{32}-a_{33}-a_{22} a_{33}
$$

In contrast to the previous case, we cannot obtain a closed form solution for the eigenvalues of the dynamic system. However, we can infer their sign by applying Descartes' rule of signs in polynomial equations. The determinant of the Jacobian matrix can be expressed as:

$$
\operatorname{Det}(J)=v_{0}\left(v_{1}+v_{2}\right)
$$

where

$$
\begin{gathered}
v_{0} \equiv-\frac{(1-\alpha)(1-\eta) A^{2} g^{-2(1-\alpha)}}{\sigma b^{2}}<0 \\
v_{1} \equiv\left(1-\psi_{2}\right)\left[\alpha \eta(1-\varphi) g+(1-\eta) \sigma \psi_{2}+(1-\alpha)(1-\eta) \sigma \psi_{2} b\right]>0
\end{gathered}
$$

and 


$$
v_{2} \equiv(1-\alpha) \alpha \psi_{2}\left[(1-\eta) \sigma \psi_{2}+\eta(\sigma+\varphi-1)\right] b^{2}-\alpha(1-\eta)\left(1-\psi_{2}\right) \sigma \psi_{2} b
$$

Regarding the sign of $v_{2}$, we can show that is negative. Rearranging (33) yields:

$$
\frac{1}{b}-\frac{(1-\alpha)\left[\sigma \psi_{2}(1-\eta)+\eta(\sigma+\varphi-1)\right]}{\sigma(1-\eta)\left(1-\psi_{2}\right)}=\frac{\rho / \sigma}{(1-\eta)\left(1-\psi_{2}\right) A g^{\alpha}}>0
$$

From the inequality involving the term on the left-hand side of the above expression, it follows that:

$$
b<\frac{\sigma(1-\eta)\left(1-\psi_{2}\right)}{(1-\alpha)\left[\sigma \psi_{2}(1-\eta)+\eta(\sigma+\varphi-1)\right]}
$$

Multiplying both sides by $b>0$ and $0<\alpha \psi_{2}<1$, and then rearranging implies that $v_{2}<0$. Based on the above result, it follows that the sign of the determinant depends on whether the sum $v_{1}+v_{2}$ is positive or negative. Using expression (A.3) to obtain $b$, substituting it into $v_{1}$ and $v_{2}$, and adding these two terms yields:

$$
v_{1}+v_{2}=\left(1-\psi_{2}\right)\left[\alpha \eta(1-\varphi) g+(1-\eta) \sigma \psi_{2}\right]+\frac{\kappa_{1}}{\kappa_{2}}
$$

where

$$
\kappa_{1} \equiv A\left(\sigma(1-\eta)\left(1-\psi_{2}\right)\right)^{2} \psi_{2} g^{\alpha}\left\{(1-2 \alpha) \rho+A(1-\alpha)^{2}\left[\eta(\sigma+\varphi-1)+(1-\eta) \sigma \psi_{2}\right] g^{\alpha}\right\}
$$

and

$$
\kappa_{2} \equiv\left[\rho+(1-\alpha)\left[\eta(\sigma+\varphi-1)+(1-\eta) \sigma \psi_{2}\right] A g^{\alpha}\right]^{2}
$$

The first term of the sum $v_{1}+v_{2}$ is positive. Furthermore, since $\sigma+\varphi>1$ from Proposition 1 and $\alpha<1 / 2$, it follows that $\kappa_{1} / \kappa_{2}>0$. Hence, $v_{1}+v_{2}>0$ which, in turn, implies that $\operatorname{Det}(J)<0$.

In applying Descartes' rule of signs, we first consider polynomial (A.4) as it stands without changing the sign of $\lambda$. This is referred to as the "positive" case. Table A.1(a) below displays all possible sign combinations of the coefficients as well as the number of sign changes from positive to negative and vice versa. In addition, we consider polynomial (A.4) having changed the sign of $\lambda$. This is referred to as the "negative" case and Table A.1(b) displays all possible sign combinations of the coefficients as well as the number of sign changes. 


\section{ANGYRIDIS, TSINTZOS Public Investment and Debt}

Based on Tables A.1(a) and A.1(b), it follows that the dynamic system (28) - (30) has either one or three negative eigenvalues. If there is a single negative eigenvalue, then the BGP is unstable. On the other hand, if there are three negative eigenvalues, then the system is locally indeterminate.

Table A.1(a): Positive Case

$$
f(\lambda)=-\lambda^{3}+\operatorname{Tr}(J) \lambda^{2}+\mathrm{Z} \lambda+\operatorname{Det}(J)=0
$$

\begin{tabular}{|c|c|c|c|c|}
\hline$-\lambda^{3}$ & $\operatorname{Tr}(J)$ & $\mathrm{Z}$ & $\operatorname{Det}(J)$ & Sign Changes \\
\hline- & - & - & - & 0 \\
\hline- & - & + & - & 2 \\
\hline- & + & + & - & 2 \\
\hline- & + & - & - & 2 \\
\hline
\end{tabular}

Table A.1(b): Negative Case

$$
f(-\lambda)=\lambda^{3}+\operatorname{Tr}(J) \lambda^{2}-\mathrm{Z} \lambda+\operatorname{Det}(J)=0
$$

\begin{tabular}{|c|c|c|c|c|}
\hline$\lambda^{3}$ & $\operatorname{Tr}(J)$ & $\mathrm{Z}$ & $\operatorname{Det}(J)$ & Sign Changes \\
\hline+ & - & - & - & 1 \\
\hline+ & - & + & - & 3 \\
\hline+ & + & + & - & 1 \\
\hline+ & + & - & - & 1 \\
\hline
\end{tabular}

\section{Appendix B}

This appendix provides a brief description of the model that includes nonzero depreciation rates for private $\left(\boldsymbol{\delta}_{\boldsymbol{K}}\right)$ and public capital $\left(\boldsymbol{\delta}_{\boldsymbol{G}}\right)$. Relative to the version of the model presented in Section 2, the key difference is the resulting change in the expressions for the before-tax rate of return to capital and the two fiscal rules. In particular, equation (3) becomes:

$$
r(t)=(1-\alpha) A K(t)^{-\alpha} G(t)^{\alpha}-\delta_{K}
$$

while the expressions for the FRO (equation (5)) and FRT (equation (6)) rules are now given by:

$$
I_{G}(t)=\dot{G}(t)+\delta_{G} G(t)=\psi_{1} A K(t)^{1-\alpha} G(t)^{\alpha}
$$

and 
Review of Economic Analysis 10 (2018) 121-150

$$
I_{G}(t)=\dot{G}(t)+\delta_{G} G(t)=\psi_{2} T(t)
$$

respectively. Note that the common for both expenditure rules threshold level of the publicto-private capital ratio stated in Proposition 1 that ensures a nonnegative long-run growth rate is now expressed as:

$$
g \geq\left[\frac{\rho+\delta_{K}(1-\varphi) \eta}{(1-\alpha)(1-\varphi) \eta A}\right]^{\frac{1}{\alpha}} \equiv \tilde{g}>0
$$

Following steps similar to the ones described in Sections 3 and 4, we obtain the dynamic systems for the two fiscal rules used in the simulations reported in Section 7. When public investment is indexed to output (FRO), dynamic system (25) - (27) is replaced by:

$$
\begin{aligned}
& \frac{\dot{c}}{c}=-\frac{\rho}{\sigma}+c+\delta_{K}\left(\frac{1}{\sigma}\right)[\sigma-\eta(1-\varphi)]+\left(\frac{1}{\sigma}\right)\left[\eta(1-\alpha)(1-\varphi)-\sigma\left(1-\psi_{1}\right)\right] A g^{\alpha} \\
& \frac{\dot{b}}{b}=c+\delta_{K}(1-\eta)-\left(1-(1-\alpha) \eta-\psi_{1}\right) A g^{\alpha}+\left(\frac{1}{b}\right)\left[\delta_{K}(1-\eta)-\left(1-\eta-\psi_{1}\right) A g^{\alpha}\right]
\end{aligned}
$$

and

$$
\frac{\dot{g}}{g}=c+\delta_{K}-\delta_{G}+\psi_{1} A g^{\alpha-1}-\left(1-\psi_{1}\right) A g^{\alpha}
$$

On the other hand, when public investment is indexed to tax revenues (FRT), dynamic system (28) - (30) becomes:

$$
\begin{aligned}
& \frac{\dot{c}}{c}=-\frac{\rho}{\sigma}+c+\left[1-(1-\eta) \psi_{2}(1+b)-\left(\frac{1}{\sigma}\right) \eta(1-\varphi)\right] \delta_{K} \\
&+\left[\left(\frac{1}{\sigma}\right) \eta(1-\alpha)(1-\varphi)-\left(1-(1-\eta) \psi_{2}\right)+(1-\eta) \psi_{2}(1-\alpha) b\right] A g^{\alpha} \\
& \frac{\dot{b}}{b}=c+(1-\eta)\left(1-2 \psi_{2}\right) \delta_{K}-\left[1-(1-\alpha) \eta-(2-\alpha) \psi_{2}\right] A g^{\alpha} \\
& \quad+\left(\frac{1}{b}\right)(1-\eta)\left(1-\psi_{2}\right)\left(\delta_{K}-A g^{\alpha}\right)-(1-\eta) \psi_{2} b\left(\delta_{K}-(1-\alpha) A g^{\alpha}\right)
\end{aligned}
$$

and 
ANGYRIDIS, TSINTZOS Public Investment and Debt

$$
\begin{aligned}
\frac{\dot{g}}{g}=c+\left[1-(1-\eta) \psi_{2}(1\right. & \left.+g)\left(\frac{1-b}{g}\right)\right] \delta_{K}-\delta_{G}-\left[1-(1-\eta) \psi_{2}\right] A g^{\alpha} \\
& +(1-\eta) \psi_{2}[1-(1-\alpha)(1+g) b] A g^{\alpha-1}
\end{aligned}
$$

It is straightforward to show that dynamic systems (B.4) - (B.6) and (B.7) - (B.9) collapse to systems (25) - (27) and (28) - (30), respectively, if one sets $\delta_{K}=\delta_{G}=0$.

\section{References}

Arnold, Jens (2008). 'Do Tax Structures Affect Aggregate Economic Growth? Empirical Evidence from a Panel of OECD Countries', Organisation for Economic Co-operation and Development (OECD), Economics Department Working Papers, No. 643.

Arrow, K. and Kurz, M. (1970). Public Investment, the Rate of Return and Optimal Fiscal Policy, The John Hopkins Press, Baltimore.

Atolia, M., Awad B. and Marquis, M. (2011). 'Linearization and higher-order approximations: How good are they?', Computational Economics, Vol. 38, pp. 1-31.

Barro, R. (1990). 'Government Spending in a Simple Model of Endogenous Growth', Journal of Political Economy, Vol. 98, pp.103-125.

Benhabib, J. and Farmer, R. (1999). 'Indeterminacy and sunspots in macroeconomics', in Taylor, J., Woodford M. (Eds.), Handbook of Macroeconomics, Vol. 1A. North-Holland, Amsterdam, pp. 387-448.

Benhabib, J. and Gali, J. (1995). 'On growth and indeterminacy: some theory and evidence', Carnegie-Rochester Conference Series on Public Policy, 43, 161-211.

Cassou, S.P. and Lansing, K.J. (2004). 'Growth effects of shifting from a graduated-rate tax system to a flat tax', Economic Inquiry, Vol. 42, No. 2, pp. 194-213.

Chang, J.-J., Guo J.-T., Shieh, J.-Y. and Wang, W.-N. (2015). 'Sectoral Composition of Government Spending and Macroeconomic (In)Stability', Economic Inquiry, Vol. 53, No. 1, pp. 23-33.

Chen, Shu-Hua and Guo, Jang-Ting (2013a). 'On indeterminacy and growth under progressive taxation and productive government spending', Canadian Journal of Economics, Vol. 46, No. 3, 865-880.

Chen, Shu-Hua and Guo, Jang-Ting (2013b). 'Progressive taxation and macroeconomic (In)stability with productive government spending', Journal of Economic Dynamics \& Control, 37, pp. 951-963.

Devereux, M. and Love, D. (1995). 'The Dynamic Effects of Government Spending Policies in a Two-Sector Endogenous Growth Model', Journal of Money, Credit, and Banking, Vol. 27, pp. 232-256.

Fatás, Antonio and Mihov, Ilian (2003). 'The case for restricting fiscal policy discretion', Quarterly Journal of Economics, Vol. 118, No. 4, pp. 1419-1447. 
Futagami, K., Morita and Y., Shibata, A., (1993). 'Dynamic Analysis of an Endogenous Growth Model with Public Capital', Scandinavian Journal of Economics, Vol. 95, pp. 607-625.

Ghosh, S. and Mourmouras, I. A. (2004). 'Endogenous Growth, Welfare and Budgetary regimes', Journal of Macroeconomics, Vol. 26, pp. 440-451.

Greiner, Alfred (2006). 'Progressive Taxation, Public Capital, and Endogenous Growth', FinanzArchiv/Public Finance Analysis, Vol. 62, No. 3, pp. 353-366.

Greiner, A. and Semmler, W. (2000). 'Endogenous Growth, Government Debt and Budgetary Regimes', Journal of Macroeconomics, Vol. 22, pp. 363-384.

Greiner, A. and Semmler, W. (1996). 'Saddle Path Stability, Fluctuations, and Indeterminacy in Economic Growth', Studies in Nonlinear Dynamics and Econometrics, Vol. 1, No. 2, pp. 105-118.

Guo, J-T. and Lansing, K.J. (1998). 'Indeterminacy and Stabilization Policy', Journal of Economic Theory, 82, pp. 481-490.

Havranek, T., Horvath R., Irsova Z. and Rusnak M. (2015). 'Cross-country Heterogeneity in Intertemporal Substitution', Journal of International Economics, Vol. 96, pp. 100-118.

Palivos, T. and Yip, C. K. and Zhang, J. (2003). 'Transitional Dynamics and Indeterminacy of equilibria in an Endogenous Growth Model with a Public Input', Review of Development Economics, Vol. 7, pp. 86-98.

Park, H. and Philippopoulos, A. (2004). 'Indeterminacy and Fiscal Policies in a Growing Economy', Journal of Economic Dynamics and Control, Vol. 28, pp. 645-660.

Schmitt-Grohé, S. and Uribe, M. (1997). 'Balanced-budget rules, distortionary taxes and aggregate instability', Journal of Political Economy, Vol. 105, pp. 976-1000.

Turnovsky, Stephen J. (2000). 'Fiscal policy, elastic labor supply, and endogenous growth', Journal of Monetary Economics, 45, pp. 185-210.

Woo, Jaejoon and Kumar, Manmohan S. (2015). 'Public Debt and Growth', Economica, Vol. 82, No. 328, pp. 705-739. 